\title{
Analysis of the early life treatment to kids with a halogenated methane analogue additive on immunoglobulin $G$ levels
}

\author{
L. Abecia ${ }^{1}$, A. Clemente ${ }^{1}$, A. I. Martín-García ${ }^{1}$, G. Martínez ${ }^{1}$, C. J. Newbold ${ }^{2}$ and D. R. Yáñez-Ruiz ${ }^{1}$ \\ ${ }^{1}$ Estación Experimental del Zaidin (CSIC), Profesor Albareda, 1. 18008 Granada, Spain, ${ }^{2}$ IBERS, Aberystwyth University, \\ Aberystwyth, SY23 3DA, United Kingdom
}

In ruminants, homeostasis between the rumen microbiome and the host is in a significant extent immunologically driven. Some studies have reported an immunomodulation of the Archaea group in the rumen after specific vaccination ${ }^{(1)}$. However, no information is available on the transfer of IgG from the mother and the development of immunity in the offspring when an antimicrobial intervention is applied in early life. The aim of this work was to study the effect of treating goats and their offspring from early life with an antimethanogenic compound (bromochloromethane, BCM) on IgG levels in serum (offspring) and milk (mothers). The long-term effect on the offspring was also assessed. Two experimental groups of treated $(\mathrm{M}+)$ and non-treated (M-) lactating goats $(n=9$ per group) were used to analyze the effect of adding BCM in the diet. Milk and blood samples were taken one day after birth (P1), 21 days later (P2) and at weaning (P3). One kid per mother in both groups was treated with BCM $(\mathrm{k}+)$ from 7 days of age while the other was untreated $(\mathrm{k}-)$, resulting in four experimental groups: $\mathrm{M}+\mathrm{k}+, \mathrm{M}+\mathrm{k}-, \mathrm{M}-\mathrm{k}+$ and $\mathrm{M}-\mathrm{k}-$. Blood samples from kids were collected at 3 times: at weaning (P3), 1 month after weaning with all kids separated by treatment $(\mathrm{P} 4)$ and 2 months later when the kids were all grouped together and the BCM treatment had stopped (P5). In the transition from colostrum to mature milk, IgG levels decreased sharply $(P<0.0001)$ from P1 to P2 $(5859$ vs $209 \mu \mathrm{g} / \mathrm{ml}$; Fig. 1) and remained stable to weaning (263). No significant effect of BCM treatment on IgG levels of motherś milk was observed. IgG levels in goats' serum were unaffected $(7634 \mu \mathrm{g} / \mathrm{ml})$ by treatment or period. On the other hand, in kids, an expected increase in IgG levels in serum with age was observed (3903, 5070 and $9663 \mu \mathrm{g} / \mathrm{ml}$ for P3, P4 and P5, respectively). The treatment with BCM resulted in higher $(P<0.05)$ levels of $\mathrm{IgG}$ in the serum of $\mathrm{M}-\mathrm{k}+$ kids one month after weaning, although this difference did not persist three months later. These results show that an antimicrobial treatment applied in early life may have an impact on the IgG response of the young ruminant. The levels of specific Ig to some microbial groups may provide more insight of the mechanisms involved in such immune response.

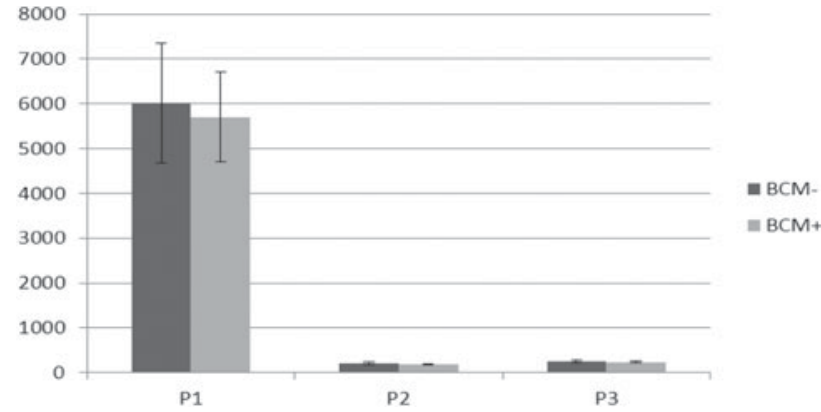

Figure 1. IgG levels in colostrum and milk $(\mu \mathrm{g} / \mathrm{ml})$.

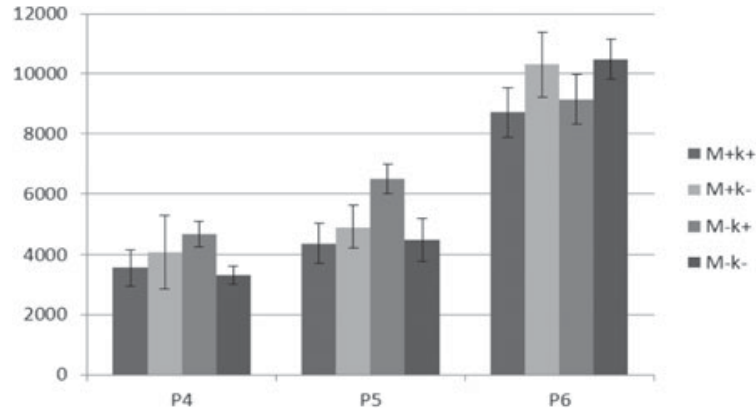

Figure 2. IgG levels in kids' serum $(\mu \mathrm{g} / \mathrm{ml})$.

This study was funded by the European Commission (Marie Curie Reintegration Grant 224816-METANORUMEN). Dr. L. Abecia acknowledges research contract JAE-Doc from CSIC.

1. Williams YJ, Popovski S, Rea SM et al. (2009) Appl Environ Microbiol 75, 1860-1866. 